\title{
Atrial Septal Defect of the Ostium Secundum Type in A 101-Year-Old Patient A Case Report
}

\author{
Takahiro Matsumoto, ${ }^{1}$ MD, Eiji Tamiya, ${ }^{1}$ MD, Tatsuji Kanoh, ${ }^{1}$ MD, Tomosato Takabe, ${ }^{1}$ MD, \\ Ken-ichi Kuremoto, ${ }^{1}$ MD, Takashi Kamiyama, ${ }^{1}$ MD, Shoichi Yamamoto, ${ }^{1}$ MD and Hiroyuki Daida, ${ }^{2}$ MD
}

\begin{abstract}
Summary
The patient was a 101-year-old woman whose chief complaints were difficulty of breathing and high fever. The history of the present illness included paroxysmal atrial flutter which was untreated, but she had not developed heart failure.

At admission, auscultation of the chest revealed moist rales and systolic murmur but did not clearly show the presence of fixed splitting of S2. X-ray examination of the chest showed a cardiothoracic ratio of $61 \%$, moderate bilateral pulmonary congestion, pleural fluid, and enlarged pulmonary arteries. Electrocardiogram showed atrial flutter with a heart rate of approximately 150 beats/minute. Echocardiographic examination revealed an atrial septal defect (ASD) of the ostium secundum type (left to right shunt) and right ventricular pressure $71 \mathrm{mmHg}$. The diameter of the ASD was approximately $10 \mathrm{~mm}$.

She began receiving an antibiotic and a diuretic immediately after admission, but died on the second day of hospitalization.
\end{abstract}

This case could be the oldest individual with ASD among those reported to date.

(Int Heart J 2019; 60: 489-491)

Key words: Prognosis, Eldest patient, Congenital heart disease

A trial septal defect (ASD) is the most common congenital heart disease among adults. ${ }^{1)}$ It does not always cause a heart murmur or any obvious electrocardiographic abnormality. Thus, it might not be detected until the individuals are elderly. ${ }^{2)}$ The patient was a 101-year-old woman with an ASD of the ostium secundum type (left to right shunt). The present report was made because the patient could be the oldest individual with ASD among those reported to date.

\section{Case Report}

The patient was a 101-year-old woman whose chief complaints were difficulty of breathing and high fever. The status before admission was all assistance and the severity of heart failure was NYHA II. The history of the present illness included paroxysmal atrial flutter which was untreated, but she had not developed heart failure. She began to experience the aforementioned symptoms and was presented to our hospital at the first occurrence, and was admitted on the same day. She did not take any medication before admission. The medical history included surgery for intestinal obstruction. The family history and social history were non-contributory.
At admission, she was alert and physical findings were as follows: body temperature 100.9 degrees (Fahrenheit), blood pressure $123 / 86 \mathrm{mmHg}$, pulse rate 139 beats/ minute (regular), and percutaneous arterial oxygen saturation $85 \%$. Auscultation of the chest revealed moist rales and systolic murmur but did not clearly show the presence of fixed splitting of S2. The abdomen was flat and soft, and the legs exhibited moderate edema. X-ray examination of the chest showed a cardiothoracic ratio of $61 \%$, moderate bilateral pulmonary congestion, pleural fluid, and enlarged pulmonary arteries. Electrocardiogram revealed atrial flutter with a heart rate of approximately 150 beats/minute. It also showed slight ST-segment depression (Figure 1).

At admission, the results of blood tests were white blood cell count $11620 / \mu \mathrm{L}$, red blood cell count $3.42 \times$ $10 \% / \mu \mathrm{L}$, hemoglobin $8.8 \mathrm{~g} / \mathrm{dL}$, total protein $6.4 \mathrm{~g} / \mathrm{dL}$, AST $25 \mathrm{IU} / \mathrm{L}$, ALT $12 \mathrm{IU} / \mathrm{L}$, total bilirubin $0.7 \mathrm{mg} / \mathrm{dL}$, creatinine $1.3 \mathrm{mg} / \mathrm{dL}$, C-reactive protein $6.2 \mathrm{mg} / \mathrm{dL}$, and $\mathrm{N}$ terminal pro-brain natriuretic peptide $30566 \mathrm{pg} / \mathrm{mL}$. The blood tests on admission are shown in the Table.

Echocardiographic examination revealed an ASD of the ostium secundum type (left to right shunt, Figure 2). The diameter of the ASD was approximately $10 \mathrm{~mm}$. Left

From the ${ }^{1}$ Department of Cardiology, Koto Hospital, Tokyo, Japan and ${ }^{2}$ Department of Cardiology, Juntendo University, Tokyo, Japan.

Partly presented using the video material at Japanese Circulation Society Kanto-Kohsin-Etsu regional meeting.

Address for correspondence: Takahiro Matsumoto, MD, Department of Cardiology, Koto Hospital, 6-8-5, Ojima, Koto-ku, Tokyo, 136-0072, Japan.

E-mail: matsuabc2020@outlook.jp

Received for publication June 6, 2018. Revised and accepted September 5, 2018.

Released in advance online on J-STAGE February 22, 2019.

doi: 10.1536/ihj.18-354

All rights reserved by the International Heart Journal Association. 


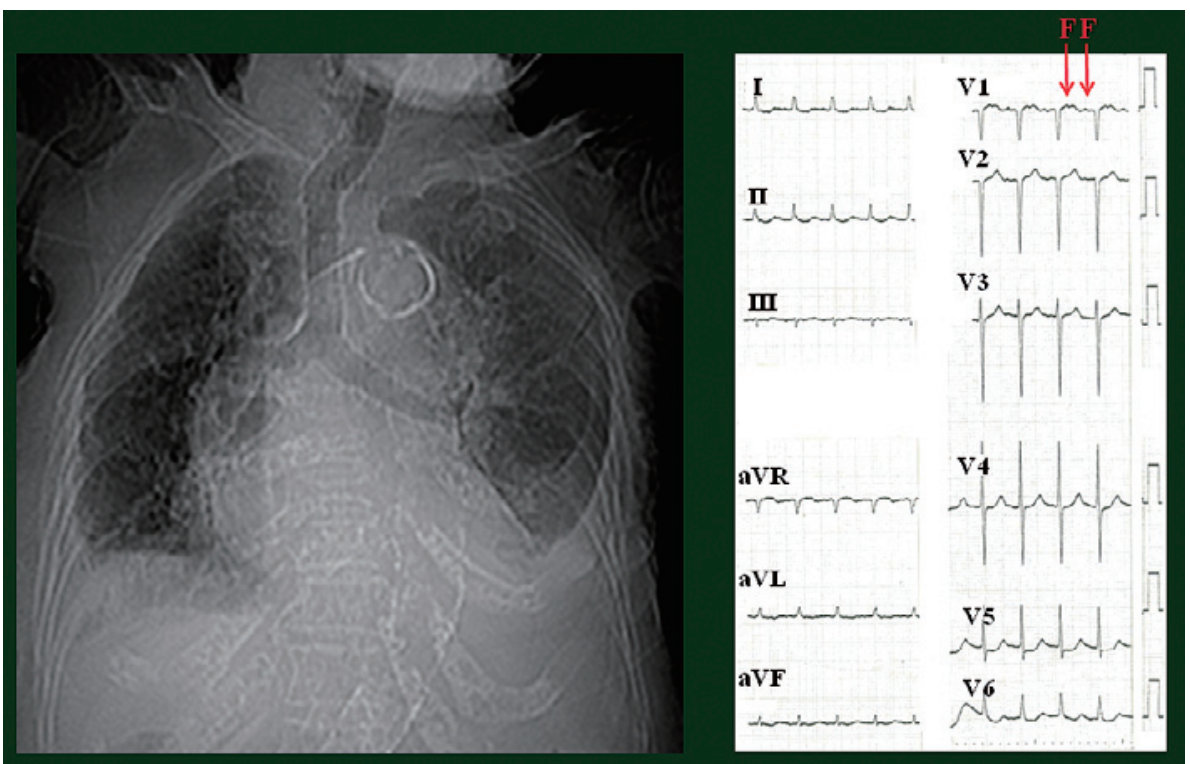

Figure 1. Chest radiogram upon admission showed a cardiothoracic ratio of $61 \%$, moderate bilateral pulmonary congestion, pleural fluid, and enlarged pulmonary arteries. Electrocardiogram revealed atrial flutter with a heart rate of approximately 150 beats/minute. $F$ indicates flutter waves.

Table. Blood Tests on Admission

\begin{tabular}{lc}
\hline Items & \\
\hline WBC & $11620 / \mu \mathrm{L}$ \\
$\mathrm{RBC}$ & $3.42 \times 10^{6} / \mu \mathrm{L}$ \\
$\mathrm{Hb}$ & $8.8 \mathrm{~g} / \mathrm{dL}$ \\
$\mathrm{Ht}$ & $30.5 \%$ \\
$\mathrm{PLT}$ & $11.9 \times 104 / \mu \mathrm{L}$ \\
$\mathrm{TP}$ & $6.4 \mathrm{~g} / \mathrm{dL}$ \\
$\mathrm{AST}$ & $25 \mathrm{IU} / \mathrm{L}$ \\
$\mathrm{ALT}$ & $12 \mathrm{IU} / \mathrm{L}$ \\
$\mathrm{T}-\mathrm{BiL}$ & $0.7 \mathrm{mg} / \mathrm{dL}$ \\
T-Cho & $187 \mathrm{mg} / \mathrm{dL}$ \\
BUN & $37.4 \mathrm{mg} / \mathrm{dL}$ \\
CRE & $1.3 \mathrm{mg} / \mathrm{dL}$ \\
UA & $9.0 \mathrm{mg} / \mathrm{dL}$ \\
Na & $143 \mathrm{mEq} / \mathrm{L}$ \\
K & $4.8 \mathrm{mEq} / \mathrm{L}$ \\
Cl & $108 \mathrm{mEq} / \mathrm{L}$ \\
CRP & $6.2 \mathrm{mg} / \mathrm{dL}$ \\
NTproBNP & $30566 \mathrm{pg} / \mathrm{mL}$ \\
BS & $100 \mathrm{mg} / \mathrm{dL}$ \\
HbA1c & $4.6 \%$ \\
\hline
\end{tabular}

ventricular diastolic and systolic diameters were small at $28.2 \mathrm{~mm}$ and $23.0 \mathrm{~mm}$, respectively (left ventricular ejection fraction: 40\%). There was an intense echocardiographic signal from mitral valve regurgitation and from tricuspid valve regurgitation (right ventricular pressure: 71 $\mathrm{mmHg}$ ). We were not able to visualize the main pulmonary artery. The blood flow signal viewed in Figure 2 was only the flow through the ASD.

The pulmonary-to-systemic blood flow ratios (Qp/Qs) was not calculated. We started an antibiotic and a diuretic immediately after admission, but died on the second day of hospitalization. Thus, she did not undergo other cardiac

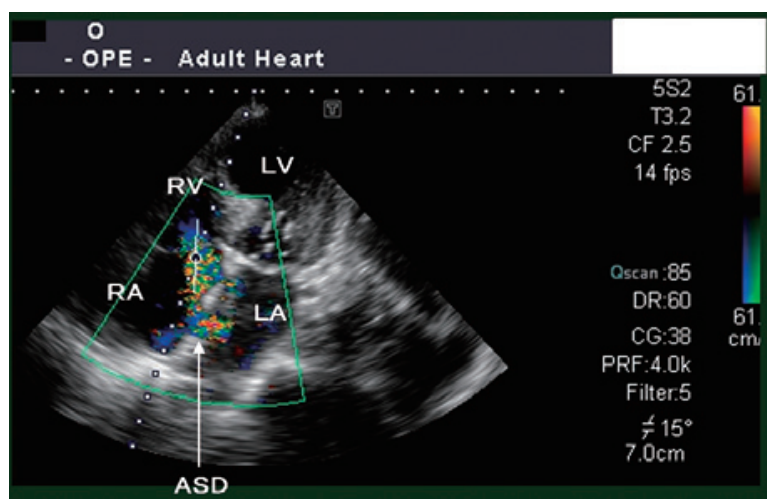

Figure 2. Echocardiogram revealed an atrial septal defect (left to right shunt). RA indicates right atrium, RV: right ventricle, LA: left atrium, LV: left ventricle, and ASD: atrial septal defect.

examinations.

\section{Discussion}

ASD is the most common congenital heart disease among adults. ${ }^{1)}$ However, it sometimes does not cause a heart murmur or any obvious electrocardiographic abnormality. Thus, it may not be detected until the individuals are elderly. ${ }^{2)}$ In our case, differential diagnosis included platypnea-orthodeoxia syndrome in which hypoxemia develops during postural change because of shunting through a patent foramen ovale. ${ }^{3)}$ However, this differential diagnosis could be ruled out based on her clinical courses.

Heart failure is said to develop in early childhood for individuals with Qp/Qs of at least 2.0 and in adolescence or adulthood for those with ratios of 1.5-2.0. ${ }^{4)}$ Generally, the tachycardia induces the smaller filling volumes and 
the decrease of ejection fraction. However, we were not able to inspect the diastolic function of the left ventricle. Although the pneumonia was hiding behind the pleural effusion, we started an antibiotic. The causes of death were thought to be pneumonia and heart failure due to aggravated rapid atrial flutter.

The prognosis of ASD is death by age 40 years in half of the cases and by age 60 years in $90 \%$ of the cases. ${ }^{5)}$ There have been other ASD cases in their very advanced age. Reports of 96- and 94-year-old individuals were made outside of Japan in $1965^{6}$ and $1984^{7)}$, respectively. A report of a 93-year-old individual was made in Japan in 1984. ${ }^{8)}$ Patients with ASD often goes unnoticed for decades because symptoms may be absent and because physical signs are subtle. A case of a 75-year-old female lived for over 70 years almost asymptomatic.9) Asymptomatic duration of our case is considered to be much longer than this case.

The present report was made because she could be the oldest individual with ASD among those reported to date.

\section{Conclusion}

In conclusion, the patient was a 101-year-old woman with an ASD of the ostium secundum type and could be the oldest individual among those reported to date.

\section{Disclosures}

Conflicts of interest: The authors declare that they have no conflict of interest.

\section{References}

1. Webb GD, Smallhorn JF, Therrien J, et al. Congenital heart disease. In: Zipes DP, Libby P, Bonow RO, Braunwald E, eds. Braunwald's Heart Disease: A textbook of Cardiovascular Medicine. 7th ed. Philadelphia, PA: Elsevier Saunders; 2005: 1489-552.

2. Nomura M, Nakaya Y, Kishi F, et al. A 90-year old patient with atrial septal defect and sinus rhythm. Acta Cardiol 1996; 121: 377-80.

3. Cheng TO. Platypnea-orthodeoxia syndrome: etiology, differential diagnosis, and management. Catheter Cardiovasc Interv 1999; 47: 64-6.

4. Campbell M. Natural history of atrial septal defect. Br Heart J 1970; 32: 820-6.

5. Craig RJ, Selzer A. Natural history and prognosis of atrial septal defect. Circulation 1968; 37: 805-15.

6. Zaver AG, Nadas AS. Atrial septal defect-secundum type. Circulation 1965; 32: 24-32.

7. Perloff JK. Ostium secundum atrial septal defect-survival for 87 and 94 years. Am J Cardiol 1984; 53: 388-9.

8. Ueda K. Clinical profiles, pathologic spectrum and management of atrial septal defect in patients aged 50 or over: How should be treated? J Cardiogr 1984; 14: 129-36.

9. Diaconu CC. Atrial septal defect in an elderly woman-a case report. J Med Life 2011; 4: 91-3. 